\title{
Cooperar ou Não, Eis a Questão: variáveis associadas à propensão a cooperar por parte de micro e pequenas empresas (MPE) do turismo ${ }^{1}$
}

\section{Cooperate or not, that is the Question: variables associated with the propensity of tourism micro and small enterprises (MSEs) to cooperate}

Cooperar o no, es la Cuestión: las variables asociadas con la propensión a cooperar por parte de micro y pequeñas empresas (MYPE) de turismo

Helena Araújo Costa ${ }^{2}$

Pedro Henrique Melo Albuquerque ${ }^{3}$

\section{Resumo}

O objetivo do artigo é explorar variáveis possivelmente associadas à propensão a participar de ações de cooperação por parte de micro e pequenas empresas do turismo. Foram selecionadas sete variáveis a partir da literatura: (1) atividade principal, (2) faturamento, (3) formalização do empreendimento, (4) localização, (5) consolidação da empresa, no que diz respeito a sua idade e número de funcionários, (6) qualificação e (7) participação em conflitos. O estudo empírico foi realizado com 209 MPE localizadas em três estados brasileiros (Ceará, Piauí e Maranhão). Valendo-se de uma abordagem quantitativa multivariada, aplicou-se um questionário estruturado e a técnica de regressão logística para a análise estatística dos dados. Os efeitos apurados mostram que, na realidade investigada, as MPE que apresentam menos propensão a cooperar com outras empresas do turismo da cidade são as mais antigas e do setor de alimentação. Por outro lado, as empresas que mais tendem a cooperar são as formais e que participaram de cursos de qualificação. Não há indícios de que as demais variáveis analisadas tenham influência sobre a propensão a cooperar.

Palavras-chave: Cooperação; micro e pequenas empresas (MPE); turismo.

\section{Abstract}

This paper aims to explore variables possibly associated with the propensity to engage in cooperative actions by micro and small tourism businesses. Seven variables were selected from the literature: (1) main activity, (2) revenues, (3) enterprise formalization, (4) location,

\footnotetext{
${ }^{1}$ Agradecimentos a Capes pelo apoio financeiro à pesquisa.

2 Doutora em Desenvolvimento Sustentável; Mestre em Turismo e Hotelaria e Graduada em Administração de Empresas. Professora adjunta II, Universidade de Brasília. Brasil. E-mail: helenacosta@unb.br.

${ }^{3}$ Doutor em Administração e Mestre em Estatística. Professor adjunto I, Universidade de Brasília. Brasil. Email: pedro.melo.albuquerque@gmail.com.
} 
(5) consolidation of the company, with regard to their age and number of employees , (6) qualification and (7) participation in conflicts. The empirical study was conducted with 209 micro and small tourism businesses located in three Brazilian states (Ceará, Piauí and Maranhão). Taking advantage of a multivariate quantitative approach was based on a structured questionnaire and a logistic regression was run for statistical analysis. The data show that the businesses which are less likely to cooperate with other businesses are the oldest and the ones related to the food sector. On the other hand, formal companies and those who participate in training courses are more likely to cooperate. There is no evidence of influence of other variables on the propensity to cooperate.

Keywords: Cooperation; micro and small enterprises; tourism.

\section{Resumen}

El objetivo de este trabajo es explorar posibles variables asociadas con la propensión a participar en acciones de cooperación por las micro y pequeñas empresas turísticas. Siete variables fueron analizadas: (1) la actividad principal, (2) de facturación, (3) la formalización de la empresa, (4) localización, (5) la consolidación de la empresa, con respecto a su edad y número de empleados (6), la calificación y (7) la participación en los conflictos. El estudio empírico se llevó a cabo con 209 MEP ubicadas en tres estados de Brasil (Ceará, Piauí y Maranhão). Tomando ventaja de un enfoque cuantitativo multivariado se aplicó un cuestionario estructurado, y la regresión logística para el análisis estadístico. Los dados encontrados muestran que las empresas más antiguas y del sector de la alimentación están menos dispuestas a cooperar con otras empresas en el sector turístico de la ciudad. Por otro lado, las empresas que están más dispuestas a cooperar son formales y las que participen en cursos de capacitación. No hay evidencia para demostrar la influencia de otras variables que tienen en la propensión a cooperar.

Palabras clave: Cooperación; micro y pequeñas empresas (MYPE); turismo.

\section{Introdução}

A abordagem sobre a estratégia de atuação isolada das empresas tem cedido espaço para um maior interesse acerca das ações conjuntas e dos relacionamentos entre elas. A literatura tem enfatizado a cooperação como um elemento essencial para o desenvolvimento e para a competitividade ao passo em que proporciona benefícios de sinergia coletiva, tais como ganhos de produtividade e inovação (JARILLO, 1988; DOTTO; WITTMANN, 2003; PAVLOVICH, 2003). 
As vantagens atribuídas à cooperação são as economias de escala e escopo, a redução dos custos de transação, a promoção de desenvolvimento local e do crescimento econômico (WANHILL, 2000; KEHRLE; MOUTINHO, 2005; CAVALCANTI FILHO; MOUTINHO, 2007; STALLIVIERI et al., 2007). Essas expectativas são especialmente relevantes quando se tratam de empresas de pequeno porte (CASAROTTO FILHO; PIRES, 1999; MILLER et al., 2007) e aparecem em estudos sobre diversos setores - tais como cerâmica, calçados, vestuário, metal-mecânico e turismo.

A cooperação entre empresas pode ser entendida como o conjunto de ações deliberadas entre organizações autônomas que decidem partilhar recursos para alcançar seus próprios objetivos e/ou objetivos comuns (JAMAL; GETZ, 1995; FRANCO, 2007). O conceito permite diversas manifestações, que variam em seus níveis de formalidade, centralidade de poder, envolvimento dos participantes, metas, tipos de ações, motivações e processos (WATKINS; BELL, 2002). Ainda que haja o reconhecimento desta variedade de configurações das ações de cooperação entre pequenas empresas aglomeradas, permanece a pergunta a que esta pesquisa se debruça: que atributos das empresas estão associados à propensão a cooperar?

Com este estudo, busca-se conhecer quais características organizacionais que mais influenciam a probabilidade de participar de ações de cooperação. As variáveis delimitadas não são consideradas preditoras do comportamento cooperativo, nem garantem o engajamento na cooperação, mas podem auxiliar na compreensão de atributos presentes em empresas que decidiram participar de ações conjuntas com outras. Diferentemente de estudos citados por Franco (2007), este trabalho não busca apontar fatores para o sucesso ou fracasso das iniciativas, tampouco os resultados advindos da cooperação (COMBS; KETCHEN, 1999) ou compreender motivações individuais para participar da cooperação (BERITELLI, 2011). Também de modo distinto dos estudos de Balestrin e Vargas (2004), Bessant e Francis (1999) e Molina-Morales (2002), esta pesquisa não tem como intenção compreender aspectos das redes de empresas em um nível coletivo, mas sim explorar atributos individuais das empresas que participam de ações cooperativas com outras. O enfoque aqui proposto é complementar a estes citados, além de ser análogo à perspectiva aplicada à cooperação entre empresas e universidade desenvolvida por Porto (2004) e Côrtes et al. (2005), que evidenciam 
características das firmas que cooperam, em comparação com aquelas que afirmam não participar de qualquer ação com tal caráter.

A importância do estudo está ligada ao papel central que a cooperação pode desempenhar em suas comunidades, tanto na realização de projetos, quanto na estruturação da governança local em busca de um padrão sustentável de desenvolvimento (BERITELLI, 2011) e na busca por competitividade para as empresas (OLAVE; AMATO NETO, 2001; RAMIREZ-RANGEL, 2001). Por estas razões, amplificadas pela relativa escassez de estudos empíricos sobre a cooperação no Brasil (VERSCHOORE; BALESTRIN, 2008), as iniciativas de cooperação empresarial carecem de uma compreensão mais profunda sobre os mecanismos e atributos que podem auxiliar em sua explicação que, por sua vez, podem influenciar na concepção de programas para apoio dessas relações.

O estudo empírico, de caráter quantitativo, que deu origem a este artigo foi realizado com 209 micro e pequenas empresas do setor do turismo ligadas a distintas atividades específicas e localizadas em três estados brasileiros (Ceará, Piauí e Maranhão). O enfoque sobre MPE ocorreu em função das características da região e devido ao fato de que empresas de porte reduzido, especialmente as micro, representam um papel fundamental no turismo tanto por sua quantidade predominante no setor (IBGE, 2007) quanto pelo contato direto com o turista, tornado-a responsável por grande parte da experiência turística ofertada pelo destino (CLARKE, 2004). A escolha da região ocorreu em virtude do estímulo para a cooperação empresarial entre MPE do turismo que tem ocorrido desde 2004, como parte das ações do programa de regionalização do turismo no Brasil e da roteirização como estratégia de desenvolvimento regional (AECID et al., 2004; MTUR, 2005). Ademais, a investigação em três realidades diferentes, porém complementares em certa medida, permite a inclusão da localização como um atributo a ser investigado.

O artigo está organizado em três seções. A primeira expõe aspectos de interesse dentro do referencial teórico sobre cooperação entre pequenas empresas aglomeradas e fundamenta as variáveis abordadas. A segunda esclarece o método empregado para a análise descrita na seção subseqüente, dedicada aos resultados. Por fim, apresentam-se as considerações finais, limitações do estudo e sugestões de pesquisas futuras. 


\section{Cooperação entre Pequenas Empresas Aglomeradas}

A concentração geográfica é um fator fundamental para a cooperação entre pequenas empresas (BALESTRIN; VARGAS, 2004), em função das relações sociais que a proximidade permite desenvolver (PYKE; SENGENBERGER, 1993; HOFFMANN et al., 2004). A aglomeração territorial pode incrementar o aprendizado e a inovação individualmente e aumentar a competitividade coletivamente, além de ter implicações para a consecução de objetivos dos demais stakeholders (EBERS; JARILLO, 1998). Este fenômeno, apesar de estudado há mais de um século por Alfred Marshall, ganhou destaque mundial apenas na década de 80, quando a Itália ilustrou os benefícios dessas estruturas, que também despontavam nos Estados Unidos e em outros países da Europa (BENKO, 2004).

Dentro das aglomerações, a cooperação é exaltada como recurso estratégico das empresas, em particular as pequenas, em função dos resultados positivos atribuídos ao comportamento cooperativo entre elas, a saber: a redução dos custos das transações, melhoria do desempenho na área de atuação, promoção do desenvolvimento local, aprimoramento do processo decisório e aumento da capacidade para ações coletivas (CÂNDIDO, 2002; MOLINAMORALES, 2002; AMATO NETO, 2005).

O comportamento associativista das empresas pode, ainda, aumentar a velocidade do fluxo de informações, diminuir as incertezas, otimizar a utilização de recursos e conhecimentos, criar mais valor para o cliente, reduzir os custos de pesquisa, entre outros benefícios (POWELL, 1990; MOLINA-MORALES, 2002; CHIAVERSIO et al., 2004; NAKANO, 2005; VERSCHOORE; BALESTRIN, 2008). Como exemplo, entre pequenas empresas australianas de diversos setores, os proprietários e/ou gerentes decidiram unir-se a redes de cooperação, principalmente, em virtude das oportunidades de aprendizagem oferecidas por estas interações. Eles percebiam, como a maior vantagem a ampliação do conhecimento sobre oportunidades relevantes de mercado (BRUNETTO; FARR-WHARTON, 2007). 
O principal foco da argumentação que apoia a cooperação entre as MPE, inclusive no turismo, defende que os seus resultados são capazes de gerar ganhos para as empresas envolvidas. Os resultados, que se confundem com motivos para cooperar, são resumidos em três aspectos: (1) produtos; (2) mercado; (3) recursos e riscos. Os produtos podem ser diversificados, com lançamento de novos itens, ou incrementados, com a incorporação de aspectos que adicionam mais valor. Os mercados podem ser ampliados ou protegidos por meio da criação de barreiras de entrada, da redução da competição e da melhoria de posicionamento. Por fim, quanto aos recursos e riscos, as razões podem ser entendidas como a redução do custo de criação de novos produtos, de produção e de inserção no mercado, agregação de recursos para investimento, e a diminuição de riscos e incertezas (FYALL; GARROD, 2005). Os autores oferecem alguns exemplos de ações conjuntas: formação de central de compras e de reservas; partilha de habilidades e treinamentos; união em associações e consórcios para angariar maior poder político, cada qual com um nível de interação e de consolidação da relação entre as partes.

No setor do turismo, há vantagens específicas advindas da cooperação entre empresas de pequeno porte por meio da aquisição de suprimentos, distribuição, ampliação e divulgação dos produtos turísticos locais (SELIN; CHÁVEZ, 1995). Entre os resultados positivos, há o desenvolvimento de marketing cooperativo e coesão da imagem do destino, melhorias de comunicação e aumento das forças de lobby, ligações entre operadoras e agências de turismo; formação de pacotes de viagens; sistemas unificados de reservas; execução de pesquisas em parceria; estabelecimento conjunto de políticas de preços e divulgação; acordos sobre mão-deobra e empregos; esquemas de treinamento comuns; canais de troca de informação; participação em associações (TREMBLAY, 1998; LEIPER, 2003).

Apesar de serem materializadas em práticas distintas, resumidamente, a cooperação entre empresas envolve três aspectos: contratos relacionais, troca de informação e ações coletivas (KNORRINGA, 1998). Contrato relacional é o oposto de relacionamentos que implicam "queda de braço", caracterizando-se pelo longo prazo da relação comercial, pela base sedimentada na confiança e pela existência ou não de hierarquização. O segundo aspecto, chamado de troca de informação, inclui aspectos formais e/ou informais, dependendo dos 
papéis dos atores envolvidos. Já as ações coletivas incluem associações que providenciem serviços reais, treinamento, difusão de informações, lobby político, entre outras. Dessa forma, os três aspectos da cooperação reforçam-se mutuamente e, quando reunidos, podem levar ao surgimento de diferentes tipos de envolvimento e de práticas entre as empresas.

Franco (2007) reconhece esta diversidade nos processos de cooperação empresarial, do improvisado ao estratégico. As relações cooperativas, portanto, também variam de formas embrionárias, exploratórias ou iniciais, até desenhos mais formais e solidificados (BRUNETTO; FARR-WHARTON, 2007). Esta variação, para Brunetto e Farr-Wharton (2007) seria explicada em função do tempo de existência da relação de cooperação e da confiança construída entre as partes, ambas ligadas à propensão do empresário a assumir riscos em conjunto com seus parceiros. Tal interpretação tem relação com uma concepção de identidade e capital social, utilizada por diversos autores (CASSON; GIUSTA, 2007; MOLINA-MORALES; MARTÍNEZ-FERNÁNDEZ, 2010). Porém, não é consensual o reconhecimento da confiança como condição absolutamente necessária para a cooperação. Há exemplos em que a cooperação entre MPE emergiu mesmo sem a confiança como uma condição preexistente (LOCKE, 2001). Isso mostra que pode haver cooperação entre empresas em um ambiente repleto de interesses próprios (AXELROD, 1990), desde que haja possibilidade de retaliação, encontros repetidos (RAPOPORT, 1998), instituições e regras estabelecidas para evitar o oportunismo (NORTH, 1990), ou que os grupos sejam pequenos, a fim de permitir a verificação da conduta individual (OLSON, 1999).

Fica evidente que diversos quadros teóricos são aplicáveis para a compreensão do modo como as relações de cooperação entre empresas se processam (OLAVE; AMATO NETO, 2001). Ademais, são múltiplas e ainda não plenamente desvendadas as condições que, combinadas, favorecem o surgimento de experiências bem sucedidas em determinadas localidades. Por esta razão, ainda é intenso o esforço ao redor de estudos de casos que permitam compreender padrões presentes nestes casos (CÂNDIDO; ABREU, 2000; SILVA, 2002; STALLIVIERI; CAMPOS et al., 2007), e sobre os quais se tem a expectativa de possível reprodução em outros locais. Dentro deste contexto, torna-se interessante conhecer alguns atributos já 
apontados na literatura como influenciadores do engajamento das MPE em ações de cooperação.

Especificamente no setor de turismo, algumas evidências aparecem em estudos realizados com pequenas empresas de turismo na Austrália. Autores mostram que há relação da atividade principal da empresa, no que tange a seus produtos e serviços principais, com a participação em cooperação (WILKINSON; MARCH, 2008). Ou seja, a natureza do negócio pode influenciar a participação ou não em ações cooperativas. As operadoras de turismo foram as empresas que geraram o maior número de ações conjuntas, com múltiplas propostas: diminuir custos, aumentar acesso aos mercados, etc. Isso poderia ser explicado pela própria atividade em questão, já que as operadoras são responsáveis por organizar a oferta turística de diversos fornecedores em forma de pacotes turísticos.

Outro estudo realizado com pequenas empresas, também na Austrália, averiguou a diferença na propensão a cooperar, quando comparadas pequenas empresas de diferentes ramos de atividade em cidades essencialmente turísticas (SOUTO-MAIOR, 2005). As empresas mais estreitamente ligadas ao turismo (hospedagem e atrações turísticas) apresentaram uma maior tendência à cooperação, enquanto empresas que trabalhavam indiretamente com o setor turístico (vestuário, beleza, supermercados, decoração) demonstraram menos propensão a cooperar, corroborando proposições de Leiper (2003). Esta diferença foi explicada pela expressividade do faturamento das empresas que era proveniente do turismo, deixando entrever que, quanto maior o faturamento ligado ao turismo, maior a propensão à participação de ações conjuntas com outras pequenas empresas locais.

A formalização dos empreendimentos também foi um aspecto já apontado anteriormente como um influenciador da participação de MPE em ações compartilhadas. Para Thomas (2007), a formalização favorece o engajamento em ações conjuntas entre empresas de turismo (THOMAS, 2007). Seu estudo mostra que, quanto maior a informalidade do setor, menor a tendência a surgir parcerias entre as pequenas empresas do turismo.

Evidenciam-se, então, três contribuições, a partir deste corpo de literatura já existente acerca de cooperação entre pequenas empresas no turismo, que merecem ser investigadas: 
- $\quad$ a atividade principal das empresas como influenciador da propensão a cooperar com outras empresas do turismo;

- a propensão a cooperar com outras empresas do turismo ligada ao percentual faturamento proveniente desta atividade para a empresa;

- a possibilidade de a formalidade dos negócios influenciar o estabelecimento da cooperação entre as empresas.

Variáveis igualmente interessantes para a abordagem desta pesquisa foram extraídas também do estudo realizado com empresas de alta tecnologia por Côrtes et al (2005). Os autores mostram que a adoção de práticas de cooperação cresce nitidamente com o porte da empresa e com seu faturamento (CÔRTES; PINHO et al., 2005). Ou seja, as empresas maiores - em termos do número de empregados - e com maior faturamento, tenderam a cooperar mais, indicando que, na medida em que "a empresa se consolida, cresce também a necessidade de realizar novas ligações”. Esta colocação leva a crer que a consolidação pode ser aferida, também, por meio da idade da empresa. Portanto, os autores contribuem com as variáveis a serem exploradas: número de empregados e idade da empresa, como indicadores da consolidação do negócio, ao lado de seu faturamento. Caberia, então, compreender se empresas mais recentes ou mais antigas, com mais ou menos empregados, dentro deste recorte de porte (micro e pequeno) apresentam comportamentos distintos no que diz respeito à cooperação com outras MPE. Ademais, Côrtes et al (2005) evidenciam que as empresas que não foram apoiadas por políticas públicas, aparentemente, apresentam menos inclinação para a cooperação. Duas interessantes leituras são oferecidas pelos autores para esses dados: ou algumas políticas públicas têm gerado resultados em termos de promoção da cooperação; ou empresas conectadas por relações de cooperação com outros entes estão se saindo melhor na disputa por recursos provenientes de instituições públicas. Ainda que estas conclusões sejam extraídas de empresas de alta tecnologia de diversos portes, e não possam ser generalizadas para aquelas aqui investigadas, consistem em idéias interessantes para fomentar a discussão dentro do âmbito de MPE ligadas a um setor específico, a exemplo do turismo. 
Não foram encontrados na literatura, no entanto, estudos que associam ou explicam relações entre cooperação de empresas com a sua participação em cursos de qualificação ou sua participação em conflitos com atores sociais, apesar de serem consideradas variáveis interessantes para comporem a exploração deste estudo. Afinal, a participação em cursos de qualificação poderia estimular a convivência, assim como o acesso e a troca de conhecimentos, um dos benefícios mais exaltados da cooperação entre MPE (NAKANO, 2005; SCOTT et al., 2008; LUI, 2009).

Já o conflito, apesasr de aparentemente paradoxal à ideia de cooperação, emerge como uma variável independente interessante de ser analisada. Esta seria uma tentativa de se superar a visão compartimentada das relações sociais, há muito identificada como parcial e incompleta (HARSANYI, 1977). Conflitos, de modo geral, são entendidos como interações que expressam discordância, divergência e ações de rivalidade (WATKINS; BELL, 2002; MCINTYRE, 2007), que emergem quando dois ou mais indivíduos ou grupos manifestam objetivos incompatíveis (KRIESBERG, 2003). Neste contexto a participação da empresa em conflitos não está sendo entendida como excludente à sua participação em ações de cooperação. Afinal, o conflito pode ser entendido como um vetor de coesão social, que encoraja a cooperação entre certas partes para fazer frente aos conflitos externos ao grupo (COSER, 1964; SIMMEL, 1969). Tal interação pode ser vista com clareza quando membros se unem em forma de cooperação ou coalizão contra inimigos comuns (COSER, 1961) ou, no caso de pequenos empreendimentos, contra a competição excessiva, tornando a cooperação um meio de reduzir prejuízos da competição interna ao grupo. Como exemplo mencionado por Simmel (1969), tem-se os vendedores de livros de certa localidade que combinam o máximo desconto que pode ser dado ao consumidor, ou dos comerciantes que combinam entre si um horário de fechamento na busca de se isentarem de prejuízos pela concorrência desmedida. Essa linha teórica suporta uma perspectiva de que empresas que experimentam a participação em conflitos também possam tender a aderir a ações de cooperação. 


\section{Metodologia}

O artigo baseia-se em uma pesquisa quantitativa (survey) com 209 MPE do turismo nas localidades de Barreirinhas (MA), Parnaíba (PI) e Jericoacoara (CE). As empresas foram as unidades de análise desta etapa da pesquisa, sendo incluídas aquelas com atividade principal de hospedagem, alimentação, transporte turístico e pacotes receptivos (passeios e guias). Para o setor de serviços, são entendidas como micro empresas aquela com até nove pessoas ocupadas e como pequenas empresas aquelas que possuem entre 10 e 49 pessoas (SEBRAE, 2007). A composição do grupo de respondentes foi feita a partir de listagens oficiais e comerciais das empresas da região. Foram coletados cadastros em órgãos que lidam diretamente com o turismo local ou regional, a saber: secretarias de turismo locais; Sebrae local e estadual; lista telefônica local onde disponível; Guia Quatro Rodas 2008; ABIH estaduais para meios de hospedagem, e o Ministério do Turismo. Para cada local foi também estipulada uma cobertura geográfica com o intuito de priorizar os locais de circulação expressiva de turistas e para que fosse feito um levantamento in loco para apurar a abertura de novas empresas e fechamento de outras.

Foram empregadas as variáveis descritas no Quadro 1, no qual são detalhadas as possíveis categorias de respostas. A coleta de dados foi feita por meio de um questionário estruturado preenchido por entrevistadores em encontros individuais com os informantes, que consistiam em proprietários/sócios ou gerentes das empresas delimitadas.

\begin{tabular}{|c|c|c|}
\hline Variável & Detalhamento & Categorias de resposta \\
\hline \multicolumn{3}{|l|}{ Dependente } \\
\hline & Participação em cooperação & $\begin{array}{l}\text { Participa de alguma ação de cooperação com outras } \\
\text { empresas do turismo na cidade: sim ou não }\end{array}$ \\
\hline Cooperação & $\begin{array}{l}\text { Ação de cooperação da qual } \\
\text { participa com outras empresas do } \\
\text { turismo na cidade }\end{array}$ & $\begin{array}{l}\text { Compras conjuntas de fornecedores } \\
\text { Montagem de pacotes turísticos para distribuidores } \\
\text { Ações conjuntas de responsabilidade ambiental: com o } \\
\text { atrativo principal/parque ou área de proteção ambiental) } \\
\text { Ações conjuntas de responsabilidade social: educação da } \\
\text { comunidade } \\
\text { Divulgação conjunta } \\
\text { Treinamentos de funcionários } \\
\text { Melhoria da infra-estrutura da cidade } \\
\text { Manutenção de equipamentos } \\
\text { Indicação de outras empresas }\end{array}$ \\
\hline
\end{tabular}




\begin{tabular}{|l|l|l|}
\hline Independentes & Onde a empresa está localizada & $\begin{array}{l}\text { Jericoacoara } \\
\text { Parnaíba } \\
\text { Barreirinhas }\end{array}$ \\
\hline Atividade principal & $\begin{array}{l}\text { Ramos próprios do setor de } \\
\text { turismo }\end{array}$ & $\begin{array}{l}\text { Hospedagem } \\
\text { Alimentação } \\
\text { Transporte turístico } \\
\text { Agência de receptivo (passeios e guias) }\end{array}$ \\
\hline Faturamento & $\begin{array}{l}\text { Expressividade do faturamento } \\
\text { anual com a atividade turística }\end{array}$ & $\begin{array}{l}\text { Metade ou mais do faturamento anual advém do turismo: } \\
\text { sim ou não }\end{array}$ \\
\hline Formalização & Cadastro formal da empresa & Possui CNPJ: sim ou não \\
\hline \multirow{2}{*}{ Consolidação } & Idade da empresa & Número de anos desde a abertura da empresa \\
\cline { 2 - 3 } & Número de empregados & $\begin{array}{l}\text { Média do número de pessoas que trabalham na empresa, } \\
\text { calculada entre a alta e a baixa estações }\end{array}$ \\
\hline Qualificação & Cursos de qualificação & $\begin{array}{l}\text { Participação de gestores ou empregados em cursos de } \\
\text { qualificação: sim ou não }\end{array}$ \\
\hline Conflito & $\begin{array}{l}\text { Participação em conflitos com } \\
\text { atores sociais diversos }\end{array}$ & $\begin{array}{l}\text { Empresa tem algum desentendimento com atores sociais } \\
\text { locais (outras empresas, governo, comunidade, ONG ou } \\
\text { órgãos ambientes): sim ou não }\end{array}$ \\
\hline
\end{tabular}

Quadro 1 - Variáveis empregadas na pesquisa

Para a análise multivariada dos dados utilizou-se um modelo de regressão logística. Seja $Y$ a variável dicotômica representando a cooperação do estabelecimento $(y=1)$, e não cooperação do estabelecimento $(y=0)$ ajustou-se o seguinte modelo:

$$
\operatorname{Pr}[Y=1]=\frac{e^{\hat{x}^{\prime} \bar{\beta}}}{1+e^{\tilde{x}^{\prime} \bar{\beta}}}
$$

onde $\tilde{x}^{\prime} \widetilde{\beta}=\beta_{0}+x_{1} \beta_{1}+\cdots+x_{p} \beta_{p}$ é o preditor linear para $p$ variáveis independentes. Para a construção da regressão logística utilizou-se o método stepwise (AGRESTI, 2007) na seleção do modelo. Dessa forma, todas as variáveis independentes relacionadas aos temas do Quadro 1 foram adicionadas. Para este modelo foram considerados válidos 198 respondentes, já que a ocorrência de não-resposta (missing) do indivíduo em algum item anula a sua consideração.

O método, interativamente, selecionou o modelo mais explicativo de forma que todas as variáveis inseridas possuíssem nível crítico de no máximo 5\%, reduzindo ao máximo a ocorrência do erro tipo I durante o processo inferencial. As sete iterações do método stepwise podem ser sumarizadas pelo Gráfico 1, no qual são apresentadas as curvas ROC (Receiver Operating Characteristic), plotadas com base nos pontos considerados sensíveis (observações corretamente ajustadas) e nas especificidades (observações erroneamente ajustadas). 
A área abaixo da curva ROC permite quantificar a qualidade do ajuste do modelo ${ }^{4}$ e é idêntica ao valor de uma medida de poder de predição chamada índice de concordância $(c)^{5}$, que estima a probabilidade das previsões e resultados serem concordantes.

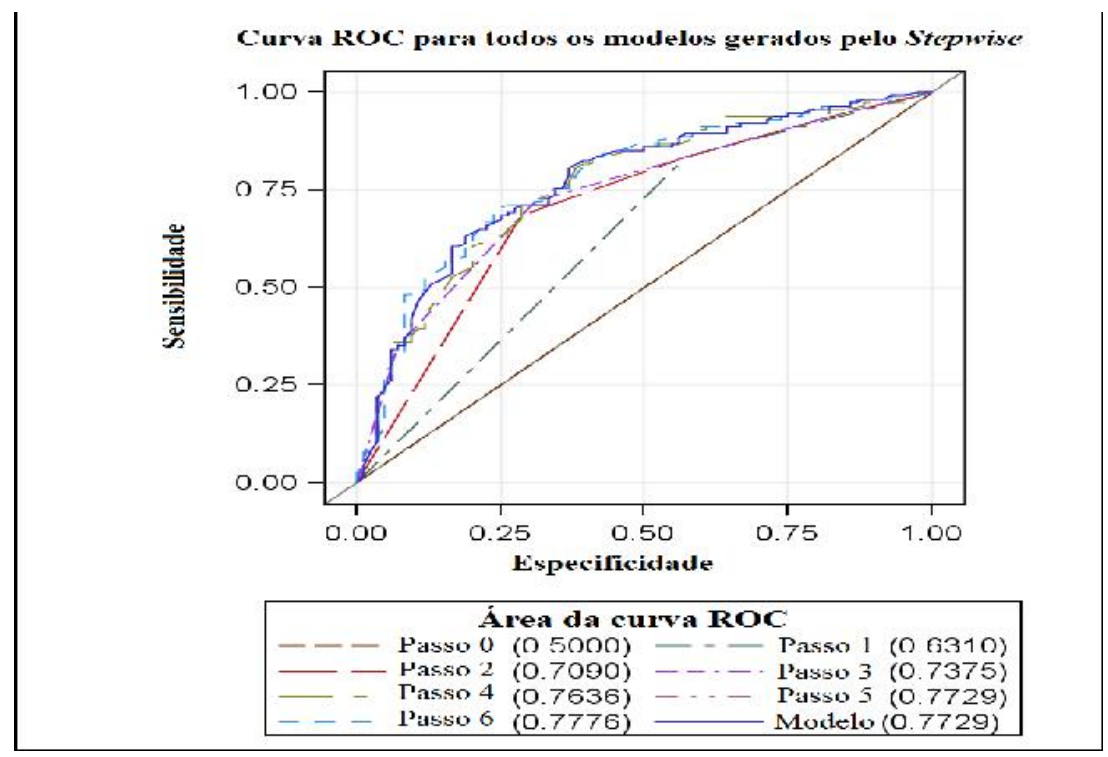

Gráfico 1 - Curva ROC para os modelos gerados pelo método stepwise Fonte: dados da pesquisa

O modelo apresentado possui índice de concordância igual a 0.7729, o que indica um alto grau de concordância entre as observações e os resultados, evidenciando sua consistência. Ademais, todas as variáveis empregadas são significantes a 5\%, o que confirma a qualidade do modelo. A qualidade do ajuste, por sua vez, foi testada pelo teste de Hosmer-Lemshow cujo valor (5.4498) e nível descritivo (0.7086) corroboram sua qualidade.

\section{Resultados e Discussão: a propensão a cooperar das MPE do turismo}

Uma caracterização geral dos respondentes mostra que $51.7 \%$ deles estão localizados em Jericoacoara, $28.2 \%$ em Barreirinhas e $20.1 \%$ em Parnaíba. Isso reflete, inclusive, a

\footnotetext{
${ }^{4}$ Quanto mais próximo de 1, melhor é o ajuste.

${ }^{5} \mathrm{O}$ índice de concordância pode ser interpretado como a porcentagem de todos os possíveis pares de casos em que o modelo atribui uma maior probabilidade para uma observação correta do que a uma observação errada.
} 
relevância do setor turístico para a economia em cada local, comparativamente. Jericoacoara, por ser um destino turístico de mais evidência nacional e internacional (INSTITUTO MARCA BRASIL et al., 2006; SEBRAE et al., 2006), além de mais consolidado, apresenta uma cadeia produtiva mais numerosa e uma maior quantidade de empresas que atendem aos critérios da pesquisa.

As empresas investigadas estão principalmente concentradas no setor de hospedagem (45\% dos respondentes), seguidas pelo setor de alimentação (26\%). Quanto ao faturamento com a atividade turística, $55.23 \%$ das empresas assentam mais da metade de seu faturamento em vendas para turistas. $\mathrm{O}$ índice de formalização é alto, tendo em vista que $84.7 \%$ possuem CNPJ. A idade média das empresas é de 7.4 anos, o que demonstra forte presença de empresas recentes. A média de funcionários por empresa é de 6.3 pessoas, evidenciando o porte micro de muitos dos empreendimentos. Entre as empresas que participaram deste estudo, $70 \%$ afirmam terem realizado cursos de qualificação.

$56.87 \%$ das MPE que participantes realizaram alguma ação de cooperação com empresas locais. Dentre as nove possíveis ações de cooperação consideradas no estudo, $98.5 \%$ dos empreendimentos indicaram outras empresas, $50 \%$ promoveram divulgação em conjunto e 45.6\% participaram de ações responsabilidade ambiental em parceria com outras empresas. Em contrapartida, no outro extremo, estão as práticas de cooperação menos realizadas pelas empresas: apenas $6.4 \%$ delas fazem compras conjuntas, $7.8 \%$ realizam manutenção compartilhada de seus equipamentos e somente $12.7 \%$ promovem treinamentos em conjunto com outros empreendimentos. Por fim, quanto à participação em conflitos por parte das empresas que responderam ao estudo, revelou-se que é predominante a presença de empresas que não estão envolvidas com nenhuma relação desta natureza (73.7\%), quer seja com outros negócios, a comunidade, ONGs ou o governo, em suas diversas escalas.

Quanto à propensão para cooperar, de acordo com as estimativas geradas pelo modelo ajustado após 7 iterações do método Stepwise, apenas as variáveis apresentadas na Tabela 1 foram significativas, a 5\% de confiança, para explicar a propensão das MPE a cooperar na região estudada. 
Tabela 1 - Estimativas do modelo de regressão logística

\begin{tabular}{|c|c|c|c|c|}
\hline Parâmetro & Estimativa & Erro-padrão & Estatística Teste (Wald) & P-valor \\
\hline Intercepto & 0.4756 & 0.6359 & 0.5594 & 0.4545 \\
\hline Atividade: hospedagem ${ }^{6}$ & -1.1138 & 0.4646 & 5.7479 & 0.0165 \\
\hline Atividade: alimentação ${ }^{7}$ & -2.1929 & 0.4978 & 19.4033 & $<.0001$ \\
\hline Qualificação $^{8}$ & 0.8894 & 0.3717 & 5.7258 & 0.0167 \\
\hline Formalização ${ }^{9}$ & 1.0097 & 0.4737 & 4.5428 & 0.0331 \\
\hline Consolidação: anos de atuação & -0.0584 & 0.0258 & 5.1406 & 0.0234 \\
\hline
\end{tabular}

Fonte: dados da pesquisa

São revelados indícios de que a atividade principal, a qualificação, a formalização e a consolidação da empresa, no que diz respeito aos seus anos de atuação no mercado, são características que influenciam significativamente sua propensão a participar de ações cooperativas com outras empresas do turismo. Isso fica demonstrado pela significância do teste bilateral de Wald possuir nível descritivo inferior a 0.05 .

Por outro lado, não há evidências que comprovem influência das demais variáveis analisadas sobre a propensão a cooperar. Não foram encontrados indícios suficientes para comprovar que a localização das empresas influencia o comportamento cooperativo das empresas nas três localidades investigadas.

A participação do faturamento advindo do turismo no faturamento total anual da MPE também não foi uma variável significativa em seu efeito sobre a propensão a cooperar. Em outras palavras, a propensão a cooperar não se altera em razão da parcela do faturamento que advém do turismo. Portanto, a expectativa de maior tendência para a cooperação entre empresas com uma maior expressividade do faturamento ligado ao turismo, a partir de proposições de Leiper (2003), não se confirma neste estudo.

O número de funcionários, utilizado como um indicador da consolidação da empresa, tampouco apresenta influência sobre a propensão a cooperar, a despeito das colocações de

6 Variáveis binárias representadas por 1 a presença da característica e zero a ausência da característica.

7 Idem a iv

8 Idem a iv

9 Idem a iv 
Côrtes et al (2005). O mencionado estudo levava a crer que, quanto maior o porte, aqui aferido pela média de funcionários, maior seria a propensão a cooperar, em função do crescimento da empresa. Porém isso não se confirma nesta realidade, talvez por se tratar de um setor com características muito distintas daquelas investigadas pelos autores ou porque eles consideraram empresas de grande porte em sua comparação, o que pode indicar a existência de um limiar (threshold) superior do número de funcionários do que aquele encontrado entre MPE.

Os dados também não apresentam indícios de que o conflito explique a probabilidade de um estabelecimento vir a cooperar. Apoiando-se na linha teórica de Simmel (1969), seria esperado que as empresas que participam de conflitos também apresentassem maior propensão a aderirem a práticas de cooperação, porém os dados aqui apurados não foram conclusivos, já a variável não teve significância para refutar a hipótese nula.

Em uma análise mais detalhada sobre as variáveis que apresentam influência significativa sobre a propensão a cooperar por parte dos participantes do estudo, cabe analisar em que sentido isso ocorre (positivo ou negativo) e mensurar qual o seu efeito. Para tanto, associadas às estimativas do modelo estão as razões de chance (Odds ratio), ou seja, a probabilidade da MPE cooperar (Tabela 2).

Tabela 2 - Estimativas da razão de chance (odds ratio)

\begin{tabular}{|c|c|c|c|}
\hline Efeito & Estimativa & \multicolumn{2}{|c|}{ Intervalo de confiança a 95\% } \\
\hline Atividade: hospedagem ${ }^{1}$ & 0.328 & 0.132 & 0.816 \\
\hline Atividade: alimentação ${ }^{1}$ & 0.112 & 0.042 & 0.296 \\
\hline Qualificação $^{1}$ & 2.434 & 1.175 & 5.042 \\
\hline Formalização $^{1}$ & 2.745 & 1.085 & 6.946 \\
\hline Consolidação: anos de atuação & 0.943 & 0.897 & 0.992 \\
\hline
\end{tabular}

Fonte: dados da pesquisa

É interessante notar que, quando a atividade principal da empresa é hospedagem, o estabelecimento tem reduzido em $67.2 \%$ a chance de vir a cooperar. Ainda mais expressivamente, quando a atividade principal da empresa é alimentação, a chance de esse 
estabelecimento vir a cooperar é reduzida em $88.8 \%$ em relação a outras atividades principais. Portanto, os empreendimentos com menor propensão a cooperar, dentre as empresas pesquisadas, são aqueles ligados à alimentação, seguidos pelos empreendimentos hoteleiros. Contudo, nota-se que nenhum dos subsetores do turismo apresentou propensão positiva à cooperação. A atividade principal, quando diz respeito a estas duas categorias mencionadas, apresenta uma relação significativa com a propensão a cooperar, e implica sua redução. Porém, quando a atividade principal é transporte turístico ou receptivo (passeios e guias), a propensão não se altera.

Neste quesito, os dados apurados confirmam parcialmente a expectativa formada a partir da literatura. Confirma-se que a atividade principal exerce efeito sobre a propensão a cooperar, porém os indícios diferem dos que foram encontrados na Austrália sobre a maior propensão à cooperação por parte de operadoras de turismo (WILKINSON; MARCH, 2008), empresas de hospedagem e atrativos (SOUTO-MAIOR, 2005). Vale esclarecer que as operadoras de pequeno porte do estudo de Wilkinson e March (2008) são consideradas equivalentes na realidade estudada às agências de receptivo, que organizam pacotes e passeios para a região. Todavia, os indícios diferem entre si, o que pode ser parcialmente explicado pela diferença de realidade entre a região estudada no Brasil e os estudos citados, feito na Austrália. Tratandose do estudo de Souto-Maior (2005), a razão para a diferença encontrada pode residir no fato de que nesta aplicação só foram abordadas empresas que estão diretamente ligadas com o turismo, não restando o comparativo com outras ligadas marginalmente com a atividade turística (supermercados, salões de beleza, etc). Ainda, há a diferenciação de que os atrativos turísticos da região aqui abordada serem parques nacionais ou áreas de proteção ambiental (APA), e não negócios privados.

Contribuindo positivamente para a propensão a participar de práticas de cooperação destacase o fato da empresa já ter participado de curso de qualificação. Nesse caso, o estabelecimento participante em cursos tem 2.4 vezes mais chance de vir a cooperar em comparação a algum estabelecimento que não tenha participado de cursos de qualificação. Em outras palavras, suponha duas empresas A e B, caso a empresa A tenha participado de curso de qualificação e a empresa B não tenha participado de curso de qualificação, então é possível inferir que A tem 
2.4 vezes mais chance de cooperar do que B. Uma extrapolação a partir deste dado poderia ser feita no seguinte sentido: a empresa que está buscando novas oportunidades de melhorar seu desempenho, via capacitação de seus gestores e funcionários, pode também estar mais propensa a cooperar com outras para a mesma finalidade, quando comparada com aquelas que não buscam qualificar-se. Essa leitura da realidade encontra substrato nas evidências de que os benefícios mais constantemente percebidos por MPE a partir da cooperação dizem respeito às oportunidades de aprendizagem oferecidas por estas interações e a ampliação do conhecimento sobre o mercado (BRUNETTO; FARR-WHARTON, 2007).

Similarmente, se a empresa é formal, ou seja, apresenta CNPJ, possui aproximadamente 2.7 vezes mais chance de cooperar do que algum outro estabelecimento informal. Isso pode ser lido como uma confirmação da apuração de Thomas (2007) sobre a importância da formalidade no encorajamento da participação em práticas de cooperação entre pequenos empreendimentos. Uma interpretação cabível para esta evidência é de que o estado jurídico de formalidade expressa também uma visão de mais longo prazo, além de novas demandas ligadas à gestão e sobrevivência do negócio que podem ser alcançada por meio de cooperação. Ainda, a formalidade carrega consigo novos custos e obrigações (impostos, etc). Por outro lado, a formalidade pode ampliar seu reconhecimento perante os demais atores sociais (bancos, associações de classe, órgãos de fomento, secretarias municipais, etc) e, possivelmente, impactar seus planos de expansão em produtos ou mercados. Também é factível pensar que a empresa formal tem mais acesso às facilidades promovidas por programas que incentivam a cooperação, especialmente oferecidos pelo Sebrae e pelas entidades setoriais.

Finalmente, para cada ano adicional de atuação da empresa a propensão a cooperar é reduzida em 5.7\%. Em outras palavras, a cada ano que a empresa A tem a mais do que a empresa B, acumulam-se reduções sucessivas das chances de que ela coopere com outras. Neste item, é contrariada a noção de Côrtes et al (2005) de que as empresas mais consolidadas, o que poderia ser entendido como as mais antigas e com mais funcionários, tenderiam a cooperar mais com outras. No estudo aqui realizado, a média de funcionários não apresentou qualquer interação com a propensão a cooperar, enquanto os anos de atuação do empreendimento 
apresentam efeito negativo sobre tal propensão. Tal evidência leva à conclusão de que as empresas estudadas, quanto mais "velhas", mais independentes se tornam das outras e menor seria sua tendência a participar da cooperação. Uma extrapolação coerente é de que a empresa mais "jovem" ainda está em uma situação de risco (haja vista a taxa de mortalidade das MPE no Brasil) e na qual necessita de apoio para suas atividades, especialmente por parte de outras instituições e, quiçá, outras empresas da localidade. Outra possibilidade de compreensão, que carece ser verificada, diz respeito a uma possível maior abertura para a cooperação por parte de negócios mais recentes por conta de sua necessidade de aprendizado e de coleta de informações.

Por fim, a análise dos dados mostra que, dentro da realidade investigada, as empresas mais antigas e do setor de alimentação tendem à ação mais isolada dentro do setor do turismo. Por outro lado, as empresas que mais tendem a cooperar são aquelas formais e que participam de cursos de qualificação. As demais variáveis não mostraram interferência sobre a propensão a cooperar.

\section{Considerações Finais}

O trabalho teve como objetivo explorar variáveis possivelmente associadas à propensão a participar de ações de cooperação, especificamente por parte de micro e pequenas empresas do turismo. A pesquisa empírica foi realizada com 209 MPE do setor do turismo localizadas nos estados do Ceará, Piauí e Maranhão. Empregou-se uma abordagem quantitativa multivariada e a técnica de regressão logística a fim de atingir o objetivo proposto. O modelo considerou 198 respondentes válidos e foi gerado em sete passos, mostrando-se robusto de acordo com os testes empreendidos.

Verificaram-se que as chances de cooperar são reduzidas para empresas do subsetor de hospedagem em $67.2 \%$, enquanto para empresas de alimentação esta redução aproxima-se 89\%. Contribuindo positivamente para a propensão a cooperação destaca-se o fato da empresa já ter participado de curso de qualificação, tendo em visto os indícios de que o estabelecimento que já participou de cursos de qualificação tem 2.4 vezes mais chance de vir 
a cooperar em comparação a algum estabelecimento que não tenha participado de tais eventos. Em uma linha semelhante, a empresa que possui CNPJ apresenta 2.7 vezes mais chance de cooperar do que um estabelecimento informal e, finalmente, para cada ano adicional de atuação da empresa a propensão a cooperar é reduzida em 5.7\%. Assim, pode-se desenhar uma análise agregada que evidencia que as empresas do turismo que apresentam menos propensão a cooperar são aquelas mais antigas e do setor de alimentação. Em contrapartida, as empresas que mais tendem a cooperar com outras empresas do turismo da cidade são aquelas formais e que participam de cursos de qualificação.

Por outro lado, não há indícios que comprovem a influência das demais variáveis analisadas sobre a propensão a cooperar. A baixa quantidade de variáveis que tiveram significância pode ser explicada pelo nível crítico adotado de 5\%, considerado bastante exigente para pesquisas desta natureza, em estágio exploratório.

O principal ganho do trabalho consiste em aventar variáveis que possam influenciar a propensão a cooperar por parte de MPE e, consequentemente, que funcionem como suporte para auxiliar a compreensão de atributos das empresas que participam de práticas de cooperação. Contudo, é relevante notar que as apurações feitas são válidas para revelar uma propensão a cooperar entre as empresas com características similares a este grupo. No entanto, não são preditoras ou prescritivas da (falta de) participação delas em ações cooperativas, nem tem a intenção de serem generalizáveis para outras realidades.

O estudo apresenta limitações quanto ao desdobramento insuficientemente detalhado de algumas variáveis em indicadores, a exemplo da noção de consolidação e da categorização utilizada para apurar o faturamento. Ademais, a perspectiva estritamente quantitativa do estudo faz com que não se tenha apurado aspectos possivelmente relevantes, tais como os tipos de cursos de qualificação e maiores detalhes sobre a sua participação em conflitos.

Para pesquisas futuras, a fim de refinar a apuração das variáveis que não apresentaram significância, poderia-se ampliar o tamanho da amostra para reduzir o Erro do Tipo II, aquele que diz respeito a considerarmos as variáveis não-significativas quando na verdade elas podem ser. Caberia também o aprofundamento de variáveis de natureza mais profunda e qualitativa, tais como as motivações dos empreendedores para engajar-se em uma ação de 
cooperação, o estilo e as habilidades gerenciais deles. Afinal, seria interessante aliar perspectiva organizacional com aquela de caráter individual dos gestores das MPE para que se construa um entendimento mais preciso acerca da complexidade ineremente à cooperação.

\section{Referências}

AECID; MTUR; ABC. Projeto de desenvolvimento do setor turístico na área de influência do parque dos Lençóis Maranhenses - Maranhão - Brasil. Agência Espanhola de Cooperação. Brasília, 2004

AGRESTI, A. An introduction to categorical data analysis. Hoboken, NJ: Wiley-Interscience, 2007

AMATO NETO, J. (org). Redes entre organizações: domínio do conhecimento e da eficácia operacional. São Paulo, Atlas, 2005.

AXELROD, R. The Evolution of Cooperation. New York: Peguin Books, 1990

BALESTRIN, A.; VARGAS, L. M. A Dimensão Estratégica das Redes Horizontais de PMEs: teorizações e Evidências. RAC. Rev. adm. contemp. [online], v.Edição Especial, p.203-227, 2004.

BENKO, G. Distritos Industriais e Governança das Economias Locais: o caso da França. Interações Revista Internacional de Desenvolvimento Local v.6, n.9, setembro, p.9-24, 2004.

BERITELLI, P. Cooperation among prominent actors in a tourist destination. Annals of Tourism Research, v. 38, n. 2, p. 607-629, 2011.

BESSANT, J.; FRANCIS, D. Using Learning Networks to Help Manufacturing Competitiveness. Technovation, v.19, p.373-381, 1999.

BRUNETTO, Y.; FARR-WHARTON, R. The Moderating Role of Trust in SME Owner/Managers' Decision-Making about Collaboration. Journal of Small Business Management, v.45, n.3, p.362-387, 2007.

CÂNDIDO, G. A formação de redes interorganizacionais como mecanismo para geração de vantagem competitiva e para promoção do desenvolvimento regional: o papel do Estado e das políticas públicas neste cenário. Revista Eletrônica de Administração, v.8, n.4, 2002.

CASAROTTO FILHO, N.; PIRES, L. H. Redes de Pequenas e Médias Empresas e Desenvolvimento Local: estratégias para a conquista da competitividade global com base na experiência italiana. . São Paulo: Atlas, 1999

CASSON, M.; GIUSTA, M. D. Entrepreneurship and Social Capital: Analysing the Impact of Social Networks on Entrepreneurial Activity from a Rational Action Perspective. International Small Business Journal, v.25, n.3, June 1, 2007, p.220-244, 2007.

CAVALCANTI FILHO, P. F. D. M. B.; MOUTINHO, L. M. G. Cooperação institucional como estratégia inovativa: o caso do APL de confecções em Campina Grande (PB). Rev. econ. contemp. [online], v.11, n.3, p. 475-507, 2007.

CHIAVERSIO, M.; DI MARIA, E.; MICELLI, S. From Local Networks of SMES to Virtual Districts? Evidence from recent trends in Italy. Research Policy, v.33, p.1509-1528, 2004.

CLARKE, J. Trade Associations: An Appropriate Channel for Developing Sustainable Practice in SMEs? Journal of Sustainable Tourism, v.12, n.3, 2004. 
COMBS, J. G.; KETCHEN, J. D. J. Explaining interfirm cooperation and performance: toward a reconciliation of predictions from the resource-based view and organizational economics. Strategic Management Journal, v.20, n.9, p.867-888, 1999.

CÔRTES, M. R.; PINHO, M.; FERNANDES, A. C.; SMOLKA, R. B.; BARRETO, A. L. C. M. Cooperação em empresas de base tecnológica: uma primeira avaliação baseada em uma pesquisa abrangente. São Paulo em Perspectiva, v.19, n.1, p.85-94, 2005.

COSER, L. The functions of social conflict: The Free Press, 1964

DOTTO, D. M. R.; WITTMANN, M. L. As Redes de Pequenas e Médias Empresas do Vale do Rio Pardo e Taquari do Rio Grande do Sul, Brasil: uma análise de estratégias de cooperação empresarial e desenvolvimento regional. VII Congreso Internacional del CLAD sobre la Reforma del Estado y de la Administración Pública, p.28-31, 2003.

EBERS, M.; JARILLO, J. C. The Construction, Forms, and Consequences of Industry Networks International Studies of Management \& Organizations, v.27, n.4, p.3-21, 1998.

FRANCO, M. J. B. Tipologia de processos de cooperação empresarial: uma investigação empírica sobre o caso português. RAC. Rev. adm. contemp. [online], v.11, n.3, 2007.

FYALL, A.; GARROD, B. From competition to collaboration in the tourism industry. In: THEOBALD, W. F. (org.). Global Tourism. Oxford: Butterworth Heinemann, 2005

HARSANYI, J. Rational behaviour and bargaining equilibrium in games and social situations. Cambridge: Cambridge University Press, 1977

HOFFMANN, V. E.; MOLINA-MORALES, F. J.; FERNÁNDEZ- MARTINEZ, M. T. Redes de empresas: uma proposta para sua classificação. XXVIII ENAMPAD - Encontro nacional dos programas de pós-graduação em administração. Curitiba, 2004.

IBGE. Economia do Turismo: análise das atividades características do turismo 2003. Rio de Janeiro, 2007

INSTITUTO MARCA BRASIL; BRAZTOA;; SEBRAE;; MTUR. Vivências Brasil: aprendendo com o turismo nacional. Roteiro Integrado: Jericoacoara - Delta do Parnaíba - Lençóis Maranhenses. 2006

JAMAL, T. B.; GETZ, D. Collaboration theory and community tourism planning. Annals of Tourism Research, v.22, n.1, p.186-204, 1995.

JARILLO, J. C. On Strategic Networks. Strategic Management Journal, v.9, p.31-41, 1988.

KEHRLE, L.; MOUTINHO, L. Competitividade presente e esperada de arranjos produtivos de calçados na Paraíba. Rev. econ. contemp. [online], v.9, n.3, p.671-697, 2005.

KNORRINGA, P. M.-S., JORG. New dimensions in local enterprise cooperation and development: from clusters to industrial districts. In: (ORG.), U. (org.). New approaches to science and technology co-operation and capacity building, 1998

KRIESBERG, L. Constructive conflicts: from escalation to resolution Lanham, Maryland: Rowman \& Littlefield Publishers, 2003

LEIPER, N. Tourism Management. London: Pearson Sprint Print, 2003

LOCKE, R. Trust building. Econômica, v.3, n.2, p.253-281, 2001. 
LUI, S. S. The Roles of Competence Trust, Formal Contract, and Time Horizon in Interorganizational Learning. Organization Studies, v.30, n.4, April 1, 2009, p.333-353, 2009.

MCINTYRE, S. E. Como as pessoas gerem o conflito nas organizações: estratégias individuais negociais. Análise Psicológica, p.295-305, 2007.

MILLER, N. J.; BESSER, T.; MALSHE, A. Strategic Networking among Small Businesses in Small US Communities. International Small Business Journal, v.25, n.6, December 1, 2007, p.631-665, 2007.

MOLINA-MORALES, F. X.; MARTÍNEZ-FERNÁNDEZ, M. T. Social Networks: Effects of Social Capital on Firm Innovation. Journal of Small Business Management, v.48, n.2, p.258-279, 2010.

MOLINA-MORALES, F. X. H., VALMIR E. Aprendizagem através de redes sociais: o efeito da proximidade geográfica. Revista Inteligência Empresarial: 4 p., 2002.

MTUR. Programa de Regionalização do Turismo: diretrizes operacionais. Brasília, 2005

NAKANO, D. N. Fluxos de conhecimento em redes interorganizacionais: conceitos e fatores de influência. In: AMATO NETO, J. (org.). Redes entre organizações: domínio do conhecimento e da eficácia operacional. . São Paulo: Atlas, 200554-67

NORTH, D. C. Institutions, institutional change and economic performance. Cambridge Cambridge Univesity Press, 1990

OLAVE, M. E. L.; AMATO NETO, J. Redes de Cooperação Produtiva: uma estratégia de competitividade e sobrevivência para pequenas e médias empresas. Gestão \& Produção, v.8, n.3, p.289-303, 2001.

OLSON, M. A Lógica da Ação Coletiva: os benefícios públicos e uma teoria dos grupos sociais. São Paulo: EDUSP, 1999

PAVLOVICH, K. The Evolution and Transformation of a Tourism Destination Network: the Waitomo Caves, New Zealand. Tourism Management, v.24, p.203-216, 2003.

PORTO, G. S. Características do processo decisório na Cooperação Empresa-Universidade. RAC, v.8, n.3, p.29-52, 2004.

POWELL, W. W. Neither Market nor Hierarchy: network forms of organization. Research of Organizational Behavior, v.12, p.295-336, 1990.

PYKE, F.; SENGENBERGER, W. Los distritos industriales y las pequenas empresas: distritos industriales y regeneracion economica local, 1993

RAMIREZ-RANGEL, H. Avaliando o terreno: fundamentos sociais e institucionais da cooperação da pequena empresa. In: GUIMARÃES, N. e MARTIN, S. (org.). Competitividade e Desenvolvimento: atores e instituições locais. São Paulo: Senac, 2001

RAPOPORT, A. Lutas, Jogos e Debates. Brasília: UnB, 1998

SCOTT, N.; BAGGIO, R.; COOPER, C. Tourism Destination networks and Knowledge Transfer. In: SCOTT, N., BAGGIO, R. e COOPER, C. (org.). Network Analysis and Tourism: From Theory to Practice. Clevedon: Channel View Publications, 20085, p.40-58

SEBRAE. Fatores Condicionantes e Taxas de Sobrevivência e Mortalidade das Micro e Pequenas Empresas no Brasil 2003-2005. Brasília, 2007 
SEBRAE; SENAC; MTUR. Planejamento Roteiro Turístico Integrado: Jericoacoara, Delta do Parnaíba, Lençóis Maranhenses. 2006

SELIN, S.; CHÁVEZ, D. Developing an Evolutionary Tourism Partneship Model. Annals of Tourism Research, v.22, p.844-856, 1995.

SILVA, G. Sobre a "Tropicalização" da Experiência dos Distritos Industriais Italianos. In: COCCO, G. U., ANDRÉ; GALVÃO, ALEXANDER (ORGS) (org.). Empresários e Empregos nos Novos Territórios Produtivos: o caso da terceira Itália, 2002

SIMMEL, G. Conflict \& the web of group-affiliations. New York: Free Press, 1969

SOUTO-MAIOR, A. P. Business Strategies and interfirm cooperation intourism: an investigation to identify degrees of industrial behavior displayed by tourism related firms within a tourist destination region. University of Technology of Sydney, Sydney, 2005.

STALLIVIERI, F.; CAMPOS, R. R.; BRITO, J. Capacitações Tecnológicas de Micro e Pequenas Empresas Inseridas em Redes Tecnoprodutivas: o caso da eletrometal-mecânica em Joinville (SC). $R$. Econ. Contemp. , v.11, n.3, p.439-474, 2007.

THOMAS, R. Tourism partnerships and small firms: power, participation and partition. Entrepreneurship and Innovation, v.8, n.1, p.37-43, 2007.

TREMBLAY, P. The Economic Organization of Tourism. Annals of Tourism Research, v.25, n.4, p.837-859, 1998.

VERSCHOORE, J. R.; BALESTRIN, A. Fatores Relevantes para o Estabelecimento de Redes de Cooperaçăo entre Empresas do Rio Grande do Sul. RAC. Rev. adm. contemp. [online], v.12, n.4, p.1043-1069, 2008.

WANHILL, S. Small and Medium Tourism Enterprises. Annals of Tourism Research, v.27, n.1, p.132$147,2000$.

WATKINS, M.; BELL, B. The experience of forming business relationships in tourism. International Journal of Tourism Research, n.4, p.15-28, 2002.

WILKINSON, I.; MARCH, R. Conceptual tools for evaluating tourism partnerships In: SCOTT, N., BAGGIO, R. e COOPER, C. (org.). Network analysis and Tourism: from theory to practice. London: Chanel View Publications, 2008.

\section{Recebido em: 12/07/2011 ( $1^{\mathrm{a}}$ versão $)$ - 14/06/2012 ( $2^{\mathrm{a}}$ versão $)$}

Aprovado em: 10/12/2012 